\title{
A case report of the differential diagnosis of Cellulosimicrobium cellulans-infected endocarditis combined with intracranial infection by conventional blood culture and second-generation sequencing
}

\author{
Huifang Zhang ${ }^{1 \dagger}$, Chunyan $\mathrm{He}^{2 \dagger}$, Rui Tian ${ }^{1}$ and Ruilan Wang ${ }^{1 *}$
}

\begin{abstract}
Background: Cellulosimicrobium cellulans is a gram-positive filamentous bacterium found primarily in soil and sewage that rarely causes human infection, especially in previously healthy adults, but when it does, it often indicates a poor prognosis.

Case presentation: We report a case of endocarditis and intracranial infection caused by C. cellulans in a 52-yearold woman with normal immune function and no implants in vivo. The patient started with a febrile headache that progressed to impaired consciousness after 20 days, and she finally died after treatment with vancomycin combined with rifampicin. C. cellulans was isolated from her blood cultures for 3 consecutive days after her admission; however, there was only evidence of $C$. cellulans sequences for two samples in the second-generation sequencing data generated from her peripheral blood, which were ignored by the technicians. No C. cellulans bands were detected in her cerebrospinal fluid by second-generation sequencing.
\end{abstract}

Conclusions: Second-generation sequencing seems to have limitations for certain specific strains of bacteria.

Keywords: Cellulosimicrobium cellulans, Second-generation sequencing, Infectious endocarditis, Case report

\section{Background}

Cellulosimicrobium cellulans, formerly known as Oerskovia xanthineolytica, is a gram-positive filamentous bacterium found primarily in soil and sewage that rarely causes human infection, with only approximately 30 cases reported to date. In the reported cases, infections occurred mainly in immunocompromised hosts, patients with medically relevant implants, and newborns. We

\footnotetext{
* Correspondence: wangyusun@hotmail.com

†Huifang Zhang and Chunyan He contributed equally to this work. 'Emergency \& Critical Care Department, Shanghai General Hospital, Shanghai Jiao Tong University School of Medicine, 650 New Songjiang Road, Songjiang District, Shanghai, China

Full list of author information is available at the end of the article
}

report a case of endocarditis and intracranial infection caused by $C$. cellulans in a 52 -year-old woman with normal immune function and no implants in vivo. We found differences between the results of conventional blood culture and second-generation sequencing. Secondgeneration sequencing seems to have limitations for specific strains of bacteria.

\section{Case presentation}

A 52-year-old rural housewife was admitted to our hospital with a sudden consciousness disorder and weakness of the right limb. One week prior, she was admitted to the local hospital with fever and headache and received

C C The Author(s). 2020 Open Access This article is licensed under a Creative Commons Attribution 4.0 International License, which permits use, sharing, adaptation, distribution and reproduction in any medium or format, as long as you give appropriate credit to the original author(s) and the source, provide a link to the Creative Commons licence, and indicate if changes were made. The images or other third party material in this article are included in the article's Creative Commons licence, unless indicated otherwise in a credit line to the material. If material is not included in the article's Creative Commons licence and your intended use is not permitted by statutory regulation or exceeds the permitted use, you will need to obtain permission directly from the copyright holder. To view a copy of this licence, visit http://creativecommons.org/licenses/by/4.0/. The Creative Commons Public Domain Dedication waiver (http://creativecommons.org/publicdomain/zero/1.0/) applies to the data made available in this article, unless otherwise stated in a credit line to the data. 
intermittent infusion for 20 days (the specific treatment is not known), but her headache did not improve. The cranial magnetic resonance imaging and angiography (MRI + MRA) suggested an acute interstitial infarction in the left parietal lobe and a mildly abnormal electroencephalogram (EEG). The patient was previously healthy and had no history of diabetes, autoimmune disease, or hormone use.

Her body temperature on admission was $39.6{ }^{\circ} \mathrm{C}$, with a Glasgow coma scale (GCS) score of 6 and bilateral pupil diameter of $5 \mathrm{~mm}$ with negative light reflection. Her neck was slightly stiff, a wind-like murmur during mitral valve systole was heard, and her skin and mucosa over her entire body were not visibly damaged. Laboratory examination showed peripheral blood leukocytes at $5.9 \times 10^{9} / \mathrm{L}$, neutrophils $83.7 \%$, and C-reactive protein (CRP) at $29.7 \mathrm{mg} / \mathrm{L}$. Cranial MRI showed abnormal signals in the right occipital parietal flap, which was considered to be a small focus of bleeding. Her bilateral posterior cerebral arteries were slightly slender (Fig. 1). The patient was diagnosed with infective endocarditis and an intracranial infection. Ceftriaxone sodium $2 \mathrm{~g}$ bid was given as empirical anti-infective therapy.

After admission, lumbar puncture showed a cerebrospinal fluid (CSF) pressure of $150 \mathrm{mmH}_{2} \mathrm{O}$, cerebrospinal fluid leukocyte count of $622 \times 10^{6} / \mathrm{L}, 90 \%$ multiple nucleated cells and $10 \%$ single nucleated cells, an erythrocyte count of $0 \times 10^{6} / \mathrm{L}$, protein quantification of $0.67 \mathrm{~g} / \mathrm{L}$, sugar of $2.9 \mathrm{mmol} / \mathrm{L}$ (peripheral blood sugar $6 \mathrm{mmol} / \mathrm{L}$ ), lactate dehydrogenase (LDH) of $45.6 \mathrm{U} / \mathrm{L}$, and chlorine of 127 $\mathrm{mmol} / \mathrm{L}$. Her cerebrospinal fluid smear was negative for bacteria, fungi, cryptococcus, or antibodies. Transoesophageal echocardiography showed the formation of vegetative growths on the anterior lobe of the mitral valve (Fig. 2).
Vancomycin (1 g, q12h) combined with ceftriaxone sodium ( $2 \mathrm{~g}, \mathrm{q} 12 \mathrm{~h}$ ) and rifampicin ( $450 \mathrm{mg}$, bid) were given as empirical anti-infective treatment. No bacterial growth was seen in the cerebrospinal fluid culture after $24 \mathrm{~h}$. Secondgeneration sequencing of her peripheral blood was negative for bacteria, fungi, viruses, parasites, and mycobacteria. The patient's CD3+ T lymphocytes accounted for $77.2 \%$ of the total lymphocytes, with $\mathrm{CD} 4+\mathrm{T}$ lymphocytes accounting for $49.72 \%$, and CD8+ $\mathrm{T}$ lymphocytes accounting for 19.99\%; her CD4+/CD8+ lymphocyte ratio was $2.49 \%$.

On the 5th day after admission, the peripheral blood culture of the patient was positive for Cellulosimicrobium cellulans, and her vancomycin trough concentration was $3.56 \mathrm{mg} / \mathrm{L}$. The dose frequency of vancomycin was increased $(1 \mathrm{~g}, \mathrm{q} 8 \mathrm{~h})$, and her repeated trough concentration was $20.76 \mathrm{mg} / \mathrm{L}$. There was no improvement in the patient's consciousness, and lumbar puncture was done again. Her CSF pressure was $350 \mathrm{mmH}_{2} \mathrm{O}$, leukocyte count in the CSF was $27 \times 10^{6} / \mathrm{L}, 5 \%$ multiple nucleated cells and 95\% single nucleated cells, and her erythrocyte count was $0 \times 10^{6} / \mathrm{L}$. The peripheral blood culture results were positive for Cellulosimicrobium cellulans for 3 consecutive days. The patient eventually died of circulatory failure 13 days after admission.

\section{Microbiology}

Aerobic and anaerobic blood cultures were positive for bacteria after 2 days of incubation. Polymorphic, branching, and filamentous gram-positive bacilli were detected in the blood culture flasks, whereas gram-stained agar plate cultures were more coccobacillary in form (Figs. 3, 4). On the blood agar plates, the colonies were yellow and became fringed with some agar penetration (Fig. 5), which is consistent with the observations of Marie-Claire

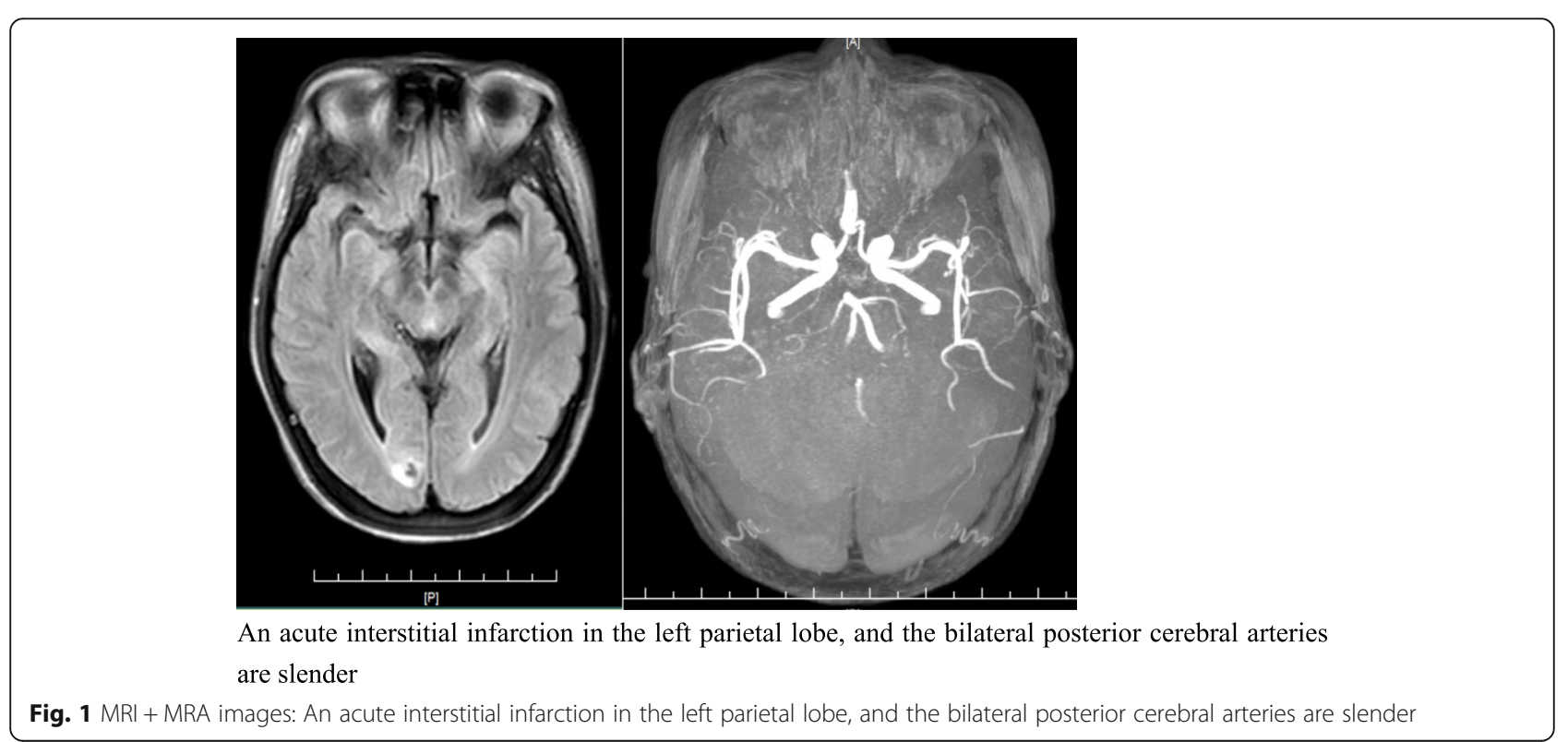




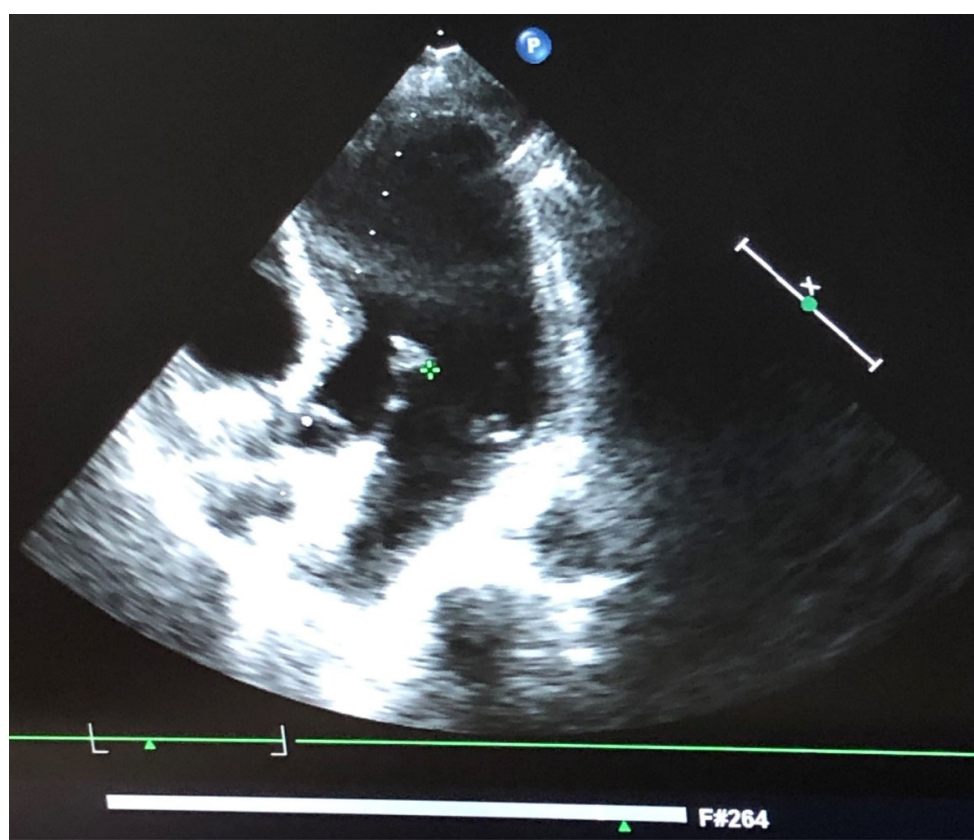

The formation of vegetative growths on the anterior lobe of the mitral valve

Fig. 2 Transoesophageal echocardiography: The formation of vegetative growths on the anterior lobe of the mitral valve

Rowlinson et al. [1]. We further identified the bacteria as "Cellulosimicrobium cellulans" by Vitek MS mass spectrometry. Antimicrobial drug susceptibility tests were performed using our in-house paper-diffusion method to detect the inhibition ring, as reported below: levofloxacin $17 \mathrm{~mm}$, ceftriaxone sodium $12 \mathrm{~mm}$, vancomycin $28 \mathrm{~mm}$, compounded cotrimoxazole $38 \mathrm{~mm}$, rifampicin $20 \mathrm{~mm}$, and tetracycline $22 \mathrm{~mm}$. In the absence of clinical and laboratory standards institute (CLSI) interpretive guidelines, the organisms were considered sensitive due to their large inhibition rings.

\section{Discussion and conclusion}

Cellulosimicrobium cellulans is a gram-positive filamentous bacterium that is a clinically rare pathogen, and there is much confusion about its classification. It was newly defined in 2001 as Cellulosimicrobium cellulans [2], of Actinobacteria class, Actinomycetales order, Micrococcineae suborder, Cellulosimicrobium genus.

Cellulosimicrobium cellulans is mainly found in soil and wastewater, and it has been shown that this strain can produce $\beta-1,3$ glucan, which is antagonistic and preventive toward plant fungal pathogens; thus, it can be
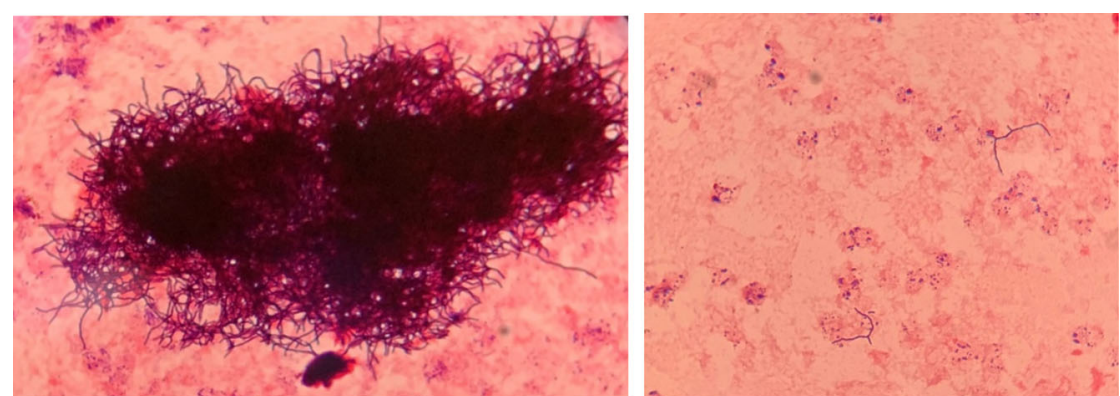

Polymorphic, branching, and filamentous gram-positive bacilli were detected from the blood culture flasks

Fig. 3 C. cellulans Gram staining from the positive aerobic blood culture bottle: Polymorphic, branching, and filamentous gram-positive bacilli were detected from the blood culture flasks 


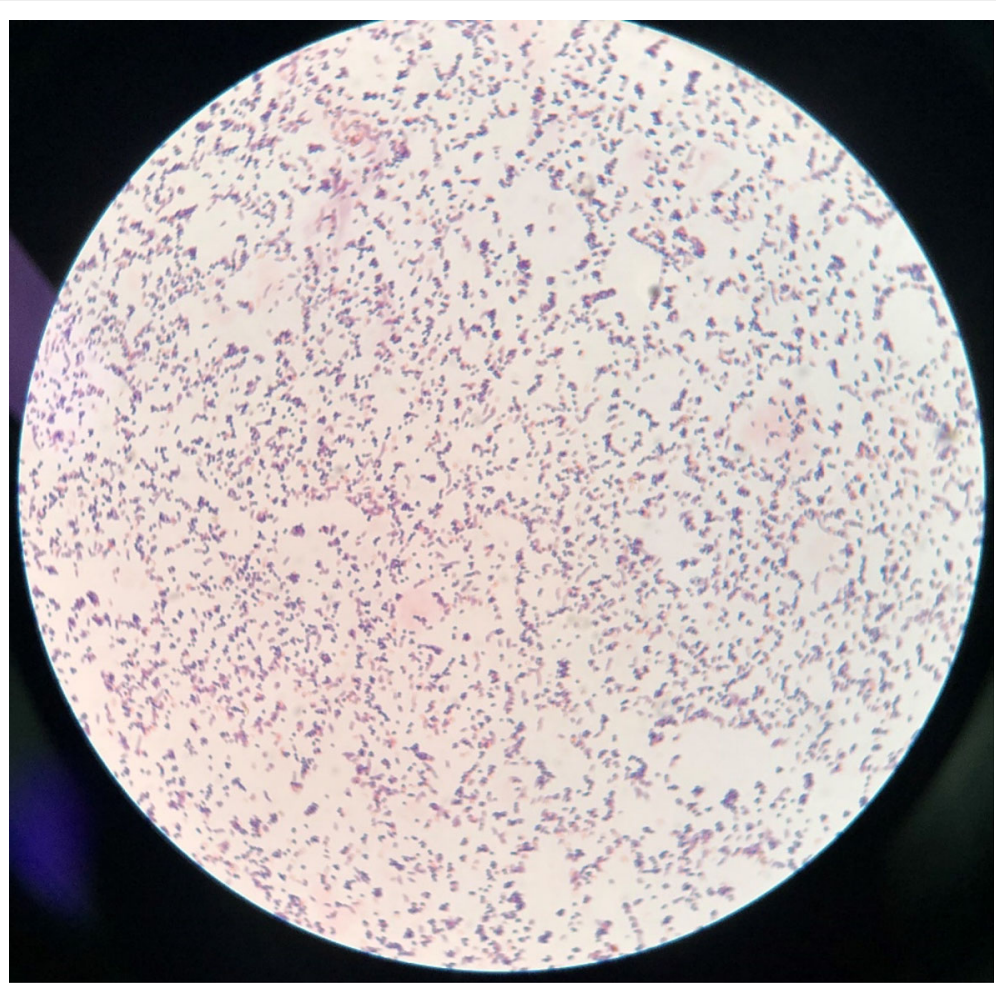

Gram-stained plate cultures from agar were more coccobacillary in form

Fig. 4 C. cellulans Gram staining from colonies isolated on sheep blood agar: Gram-stained plate cultures from agar were more coccobacillary in form

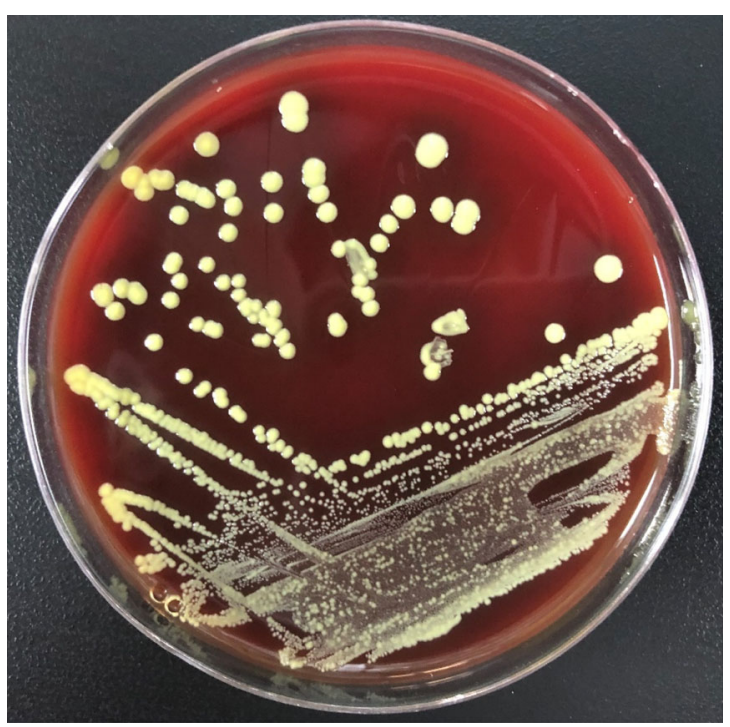

On blood agar plates, the colonies were yellow and became fringed with some agar penetration

Fig. 5 C. cellulans growth on a 5\% sheep blood agar plate: On blood agar plates, the colonies were yellow and became fringed with some agar penetration 
used as a preventive strain for plant diseases [3]. It is relatively non-toxic and rarely causes human-associated infections, with only approximately 30 cases reported so far. In the reported cases, infections mainly occurred in immunocompromised hosts (human immunodeficiency virus infection, tumour-induced immunosuppression, bone marrow and solid organ transplantation, end-stage renal disease), patients with medically relevant implants (central venous catheters, transabdominal catheter, ventriculoperitoneal shunts and prostheses) and newborns. The types of infection include peritonitis, meningitis, endocarditis, endophthalmitis, catheter-associated bacteraemia, prosthetic joint infection, pyelonephritis, soft tissue infection, and suppurative arthritis [1, 4-17].

This is a case of an immunocompetent, middle-aged, rural woman, infected with $C$. cellulans without implants that caused infective endocarditis and intracranial infection. The patient started with a febrile headache that progressed to impaired consciousness after more than 20 days, and mitral valve vegetative growth was seen in transoesophageal ultrasonography. Her cranial MRI + MRA suggested the possibility of a haemorrhagic focus in the right occipital leaflet, her bilateral posterior cerebral arteries were slender, and her blood cultures were positive for C. cellulans. Although we did not obtain culture results from the mitral valve vegetations and intracranial blood vessels, according to the principle of disease monism, we believe that the pathogen of the mitral valve vegetations was C. cellulans, that the haemorrhage focus of the right occipital leaflet was caused by bacterial embolism cerebral infarction, and that the patient's bilateral posterior cerebral arteries were also affected by bacterial destruction, which is consistent with the clinical presentation of the patient.

The cause of the consciousness disturbance in this patient also needs to be differentiated with reference to other gram-positive bacterial infections, such as tetanus infection and Nocardia infection. Tetanus is a specific infection in which Clostridium tetani invades the body through skin or mucosal wounds, grows and multiplies in an oxygendeficient environment, and produces toxins that cause spasticity. Tetanus toxin mainly attacks the motor neurons in the nervous system, so the clinical features include closed teeth, paroxysmal spasm and compulsory spasm. The spasms can be triggered by mild stimuli such as light, sound, contact, drinking water, etc., or they can be spontaneous. The patient showed no muscle spasms and had no clear history of trauma, so a diagnosis of tetanus infection was ruled out.

Nocardia is a gram-positive aerobic filamentous bacterium that is widespread in soil and in livestock, and it commonly causes infections in immunocompromised hosts, typically through the respiratory tract, skin, and digestive tract. People with poor farming practices are susceptible to infection. When intracranial infection is associated with haematogenous dissemination, it may manifest as headache, weakness, convulsions, confusion, and paralysis. No Nocardia was cultured from this patient's blood samples, and no Nocardia sequence was detected by second-generation sequencing, so Nocardia infection was not considered in this patient.

In our case, although no implants were present and no obvious skin lesions were observed, we highly suspect that the patient may have been injured by a foreign object during fieldwork. Since the patient lived alone in the countryside and was unconscious upon arrival at the hospital, her relevant medical history could not be collected. The patient's daughter said she wore rubber shoes and long-sleeved clothes most of the time when she worked in the field. Since she fell ill in July, it cannot be ruled out that she did not take protective measures due to the hot weather. It had been more than 20 days since the onset of the disease when she reached our hospital, and the causative skin wound may have healed.

Treatment of C. cellulans infections varies, but in more than half of the reported cases, the infected foreign bodies must be removed. Vancomycin is the antibiotic of choice in most cases, and all cases that do not require foreign body removal have included vancomycin as part of the antibiotic regimen $[11,12,18]$. Combined administration of vancomycin and rifampicin can even clear $C$. cellulans bloodstream infections without removing the central venous catheter [1]. In our case, the patient's treatment was delayed, she was already suffering from severe neurological impairment, and therefore, ultimately, she had a poor prognosis.

The patient had three consecutive positive blood cultures for C. cellulans, but there was evidence of C. cellulans sequences for two samples in the second-generation sequencing of her peripheral blood, and no bands were detected in her CSF. Only Bacillus subtilis (sequence number 3563) and Staphylococcus aureus (sequence number 1358) were detected in the second-generation cerebrospinal fluid sequencing. The now highly regarded second-generation sequencing seems to have limitations for specific strains. Due to the low content of intracellular bacteria released into body fluids and the low efficiency of nucleic acid extraction of fungi due to their thicker cell walls, there are often low clinical detection rates and low sensitivity. Rare pathogens and reduced bacterial populations after treatment may be interpreted by second-generation sequencing as background bacteria. When interpreting the test report, it is necessary to judge whether it is colonization bacteria, background bacteria or pathogenic bacteria based on the sample type, microbial background, clinical characteristics of the patients, traditional pathogen detection reports and auxiliary examination. 
The epidemiology and pathogenicity of C. cellulans infections are of increasing importance in clinical microbiology. We should be aware of these opportunistic pathogens, as the number of infections they cause may increase as immunosuppressed patients survive longer and the use of medical implants increases.

\section{Abbreviations}

CRP: C-reactive protein; CSF: Cerebrospinal fluid; EEG: Electroencephalogram; GCS: Glasgow coma scale; MRA: Magnetic resonance angiography;

MRI: Magnetic resonance imaging

\section{Acknowledgements}

None.

\section{Authors' contributions}

$\mathrm{H}$ Z managed the patient and drafted and revised the manuscript. $\mathrm{CH}$ was involved in bacterial culture and identification and contributed to the drafting of the manuscript. R T and RW contributed to coordinating the manuscript submission and drafting. All authors have read the manuscript and approved its final version.

\section{Funding}

Not applicable.

\section{Availability of data and materials}

The data that support the findings of this study are available from Huifang Zhang, but restrictions apply to the availability of these data, which were used under license for the current study, and therefore are not publicly available. Data are, however, available from the authors upon reasonable request and with the permission of Huifang Zhang.

\section{Ethics approval and consent to participate}

Not Required.

\section{Consent for publication}

Written informed consent was obtained from the patient for the publication of this case report and any accompanying images.

Written informed consent was obtained from the patient's next of kin for the publication of this case report and any accompanying images. A copy of the written consent is available for review by the Editor-in-Chief of this journal.

\section{Competing interests}

The authors declare that they have no competing interests.

\section{Author details}

${ }^{1}$ Emergency \& Critical Care Department, Shanghai General Hospital, Shanghai Jiao Tong University School of Medicine, 650 New Songjiang Road, Songjiang District, Shanghai, China. 'Laboratory Medicine Department, Shanghai General Hospital, Shanghai Jiao Tong University School of Medicine, Shanghai, China.

Received: 28 May 2020 Accepted: 30 October 2020

Published online: 26 November 2020

\section{References}

1. Rowlinson MC, Bruckner DA, Hinnebusch C, Nielsen K, Deville JG. Clearance of Cellulosimicrobium cellulans bacteremia in a child without central venous catheter removal. J Clin Microbiol. 2006;44(7):2650-4.

2. Schumann P, Weiss N, Stackebrandt E. Reclassification of Cellulomonas cellulans (Stackebrandt and Keddie 1986) as Cellulosimicrobium cellulans gen. nov., comb. nov. Int J Syst Evol Microbiol. 2001;51(Pt 3):1007-10.

3. Ferrer P. Revisiting the Cellulosimicrobium cellulans yeast-lytic beta-1,3glucanases toolbox: a review. Microb Cell Factories. 2006;5:10.

4. Ellerbroek P, Kuipers S, Rozenberg-Arska M, Verdonck LF, Petersen EJ. Oerskovia xanthineolytica: a new pathogen in bone marrow transplantation. Bone Marrow Transplant. 1998;22(5):503-5.

5. Funke G, Marty N. Three strains of Oerskovia xanthineolytica from clinical specimens. Clin Microbiol Newsl. 1995;17(18):142-4.
6. Harrington RD, Lewis CG, Aslanzadeh J, Stelmach P, Woolfrey AE. Oerskovia xanthineolytica infection of a prosthetic joint: case report and review. J Clin Microbiol. 1996:34(7):1821-4.

7. Heym B, Gehanno P, Friocourt V, Bougnoux ME, Le Moal M, Husson C, Leibowitch J, Nicolas-Chanoine MH. Molecular detection of Cellulosimicrobium cellulans as the etiological agent of a chronic tongue ulcer in a human immunodeficiency virus-positive patient. J Clin Microbiol. 2005:43(8):4269-71.

8. Hussain Z, Gonder JR, Lannigan R, Stoakes L. Endophthalmitis due to Oerskovia xanthineolytica. Can J Ophthalmol. 1987;22(4):234-6.

9. Kailath EJ, Goldstein E, Wagner FH. Meningitis caused by Oerskovia xanthineolytica. Am J Med Sci. 1988;295(3):216-7.

10. LeProwse CR, McNeil MM, McCarty JM. Catheter-related bacteremia caused by Oerskovia turbata. J Clin Microbiol. 1989;27(3):571-2.

11. Lujan-Zilbermann J, Jones D, DeVincenzo J. Oerskovia xanthineolytica peritonitis: case report and review. Pediatr Infect Dis J. 1999;18(8):738-9.

12. Maguire JD, McCarthy MC, Decker CF. Oerskovia xanthineolytica bacteremia in an immunocompromised host: case report and review. Clin Infect Dis. 1996;22(3):554-6.

13. Rihs JD, McNeil MM, Brown JM, Yu VL. Oerskovia xanthineolytica implicated in peritonitis associated with peritoneal dialysis: case report and review of Oerskovia infections in humans. J Clin Microbiol. 1990;28(9):1934-7.

14. Urbina BY, Gohh R, Fischer SA. Oerskovia xanthineolytica endocarditis in a renal transplant patient: case report and review of the literature. Transpl Infect Dis. 2003;5(4):195-8.

15. Magro-Checa C, Chaves-Chaparro L, Parra-Ruiz J, Pena-Monje A, RosalesAlexander JL, Salvatierra J, Raya E. Septic arthritis due to Cellulosimicrobium cellulans. J Clin Microbiol. 2011:49(12):4391-3.

16. Casanova-Roman M, Sanchez-Porto A, Gomar JL, Casanova-Bellido M. Earlyonset neonatal sepsis due to Cellulosimicrobium cellulans. Infection. 2010; 38(4):321-3.

17. Jaru-Ampornpan P, Agarwal A, Midha NK, Kim SJ. Traumatic Endophthalmitis due to Cellulosimicrobium cellulans. Case Rep Ophthalmol Med. 2011;2011:469607.

18. Guss WJ, Ament ME. Oerskovia infection caused by contaminated home parenteral nutrition solution. Arch Intern Med. 1989;149(6):1457-8.

\section{Publisher's Note}

Springer Nature remains neutral with regard to jurisdictional claims in published maps and institutional affiliations.

\section{Ready to submit your research? Choose BMC and benefit from:}

- fast, convenient online submission

- thorough peer review by experienced researchers in your field

- rapid publication on acceptance

- support for research data, including large and complex data types

- gold Open Access which fosters wider collaboration and increased citations

- maximum visibility for your research: over $100 \mathrm{M}$ website views per year

At BMC, research is always in progress.

Learn more biomedcentral.com/submissions 